\title{
The experiences of clients and healthcare providers regarding the provision of reproductive health services including the prevention of HIV and AIDS in an informal settlement in Tshwane
}

\author{
M.L.S. Mataboge ${ }^{a, *}$, S. Beukes ${ }^{b, 1}$, A.G.W. Nolte ${ }^{c, 2}$ \\ ${ }^{a}$ Department of Nursing Science, University of Pretoria, Pretoria, South Africa \\ ${ }^{\mathrm{b}}$ Non-academic, Extreme Wellness and Somar Solutions, South Africa \\ ${ }^{c}$ Department of Nursing Science, University of Johannesburg, Johannesburg, South Africa
}

\section{A R T I C L E I N F O}

\section{Article history:}

Received 3 May 2015

Accepted 6 May 2015

Available online 1 October 2015

Keywords:

Experiences reproductive health services

Prevention of HIV and AIDS

\begin{abstract}
A B S T R A C T
Globally challenges regarding healthcare provision are sometimes related to a failure to estimate client numbers in peri-urban areas due to rapid population growth. About onesixth of the world's population live in informal settlements which are mostly characterised by poor healthcare service provision. Poor access to primary healthcare may expose residents of informal settlement more to the human immunodeficiency virus (HIV) and to acquired immunodeficiency syndrome (AIDS) than their rural and urban counterparts due to a lack of access to information on prevention, early diagnosis and treatment. The objective of this study was to explore and describe the experiences of both the reproductive health services' clients and the healthcare providers with regard to the provision of reproductive health services including the prevention of HIV and AIDS in a primary healthcare setting in Tshwane. A qualitative, exploratory and contextual design using a phenomenological approach to enquire about the participants' experiences was implemented. Purposive sampling resulted in the selection of 23 clients who used the reproductive healthcare services and ten healthcare providers who were interviewed during individual and focus group interviews respectively. Tesch's method for qualitative data analysis was used. Ethical principles guided the study, and certain strategies were followed to ensure trustworthiness. The findings revealed that females who lived in informal settlements were aware of the inability of the PHC setting to provide adequate reproductive healthcare to meet their needs. The HCPs acknowledged that healthcare provision was negatively affected by policies. It was found that the community members could be taught how to coach teenagers and support each other in order to bridge staff shortages and increase health outcomes including HIV/AIDS prevention.
\end{abstract}

( 2015 The Authors. Publishing services by Elsevier B.V. on behalf of Johannesburg University. This is an open access article under the CC BY-NC-ND license (http:// creativecommons.org/licenses/by-nc-nd/4.0/).

\footnotetext{
* Corresponding author. Tel.: +27 824182865.

E-mail addresses: sanah.mataboge@up.ac.za (M.L.S. Mataboge), sbeukes@nettron.co.za (S. Beukes), agwnolte@uj.ac.za (A.G.W. Nolte).

1 Tel.: +27 836570460 .

2 Tel.: +27 828041916.
}

Peer review under responsibility of Johannesburg University. http://dx.doi.org/10.1016/j.hsag.2015.05.002

1025-9848/@ 2015 The Authors. Publishing services by Elsevier B.V. on behalf of Johannesburg University. This is an open access article under the CC BY-NC-ND license (http://creativecommons.org/licenses/by-nc-nd/4.0/). 


\section{Introduction}

The provision of healthcare services is a fundamental human right entrenched in the Constitution of the Republic of South Africa and strengthened by the Batho Pele principles (Department of Public Service and Administration [DoPSA], 1997, p. 18). Health services should thus be accessible to all citizens. The population growth experienced after the first democratic elections in South Africa in 1994 resulted in some populations having limited access to health services in some parts of the country as there was influx of migrants to urban areas who settled in informal settlements thus increasing the population in these cities exponentially. These areas are populated mostly by people who are often unemployed, live in poor living conditions and who have insufficient access to health services (Taleshi, 2009, p. 1235). By mid-2013 the three provinces with the highest populations were Gauteng with 12728 400, KwaZulu-Natal with 10456 900, and the Western Cape with 6016 900. The least populated of all nine provinces were the Free State with 2753200 and the Northern Cape with 1162900 (Statistics South Africa, 2013, p. 3).

In accordance with the Batho Pele principles, these residents should have free access to comprehensive primary healthcare services (PHC) including reproductive health services (Jooste, 2010, p. 33). According to Taleshi (2009, p. 1235), about one-sixth of the estimated global population lives in informal settlements. Meanwhile in South Africa, PHC services in informal settlements are already overstrained by the growing number of clients and if the demand for health services in these areas continues to rise, access to PHC services will be increasingly compromised (Van Rensburg, 2009, p. 198).

According to Kabiru, Beguy, Chrichton, and Zulu (2011, p. 2), in informal settlements one of the reproductive health problems is HIV infection, with females between 20 and 24 years being at a higher risk (7.4\%) than males $(1.9 \%)$ of contracting the disease. It is assumed that HIV infection in these age groups takes place during adolescence due to early sexual encounters which seems to be a common phenomenon among teenagers (Kabiru et al., 2011, p. 2). Nationally, an estimated 5380000 people are living with HIV and AIDS, which is calculated to be $10.6 \%$ of the national population of 53 million (Statistics South Africa, 2013, p. 5). According to Scott and Harrison (2009, pp. 9-10), the prevalence of HIV in the provinces ranges from the highest at $15.9 \%$ in KwaZulu-Natal to the lowest of $3.9 \%$ in the Western Cape. Gauteng has a prevalence rate of $12.1 \%$. The prevalence of HIV in urban informal settlements is $20.6 \%$, which is almost twice as high as in rural areas where the HIV prevalence rate stands at $9 \%$. Irrespective of the HIV/AIDS statistics, the provision of health services to prevent reproductive health problems continues to exclude the involvement of communities. A study conducted on migrant workers' vulnerability to HIV indicates a failure to capture the needs through migrant worker involvement and develop appropriate health programmes for migrant workers who in most instances live in informal settlements (Vearey, 2011, p. 4). Providing the reproductive health services that do not address the clients' needs renders such health services incapable of focussing on their clients' knowledge and skills to prevent HIV and AIDS.
A further concern is that rightful access to PHC services may become even more restricted if, as the United Nations predicts, by 2100 the world population will increase to an estimated 11 billion (Bongaarts \& Sinding, 2011, p. 574). In addition, Vearey (2011, p. 2) has estimated that urbanisation in Africa will increase to $50 \%$ by 2030 . In sub-Saharan Africa, South Africa has already experienced one of the fastest urban population growth rates in recent years at an estimated $60 \%$ which is giving rise to the emergence of informal settlements (Vearey, 2011, p. 2). As the informal settlement populations grow, the demand for PHC services, including reproductive health services, is also increasing. Moreover, since the PHC services in these areas are already struggling to meet the needs of the people, the prevention of HIV/AIDS as part of the reproductive health service may lag behind.

The Human Resources for Health Strategy for the Health Sector South Africa (HRH Strategy for Health Sector) confirms that there has been a growth in the number of healthcare workers since 2002; however, a shortage of staff still exists when linked to the difficulties in estimating staff demand versus population growth (Department of Health [DoH], 2012, p. 20). Staff shortages may be exacerbated by a planned nursebased healthcare approach to address the HIV/AIDS epidemic. The extended responsibilities of healthcare providers in relation to HIV and AIDS management will reduce the time that nurses can spend with the client as nurses spend one fifth of their time in training resulting in staff shortages in PHC settings (De Wet, Wouters, \& Engelbrecht, 2011, p. S98).

In order to bridge staff shortages and ensure access to healthcare, Merkel, Otai, Archer, and Lynam (2008, p. 4) propose that healthcare provision in informal settlements should not only consider formal healthcare provision, but should also involve community stakeholders as they know the challenges that put the population at risk of unintended pregnancy, STIs, HIV and AIDS. Even though community involvement and participation are entrenched in the policy intent for upgrading informal settlements and in the national health plan, and need to be implemented under the leadership of local councillors as stipulated under the local councillors' role, this has not yet been realised (Department of Housing and Settlement [DoHS], 2009, pp. 12-15). Absence of community participation leaves the vulnerable groups highly susceptible to reproductive health problems and HIV/AIDS.

\section{Problem statement}

Clients in informal settlements are often not provided with accessible healthcare services as evidenced by the escalating number of community protests for better service delivery in South Africa (South African Broadcasting Company [SABC] News, September 2013). In the current study the clients in the informal settlement had to access the clinic that was built 15 years ago and originally intended for a population size far smaller than that of the current population. Apart from the building's constraints, healthcare services delivery is limited to only $40 \mathrm{~h}$ a week and the staff is unable to cope with the growing number of clients and their reproductive health needs. Moreover, the provision of the PHC services, including reproductive health and prevention of HIV/AIDS, is free which 
is placing the health facilities and their staff under ever increasing stress as the settlements continue to grow. In addition, the residents in the informal settlements are faced with multiple risk factors that render them vulnerable to HIV and AIDS. These risk factors include the lack of family cohesion and support, a sense of social and economic marginalisation which in most instances is exacerbated by alcohol and drug abuse (Scott \& Harrison, 2009, p. 10).

\section{Research objective}

The objective of the study was as follows:

- To explore and describe the experiences of both the reproductive health services' clients and healthcare providers with regard to the provision of reproductive health services including the prevention of HIV and AIDS in an informal settlement in Tshwane.

\section{Significance of the study}

The study findings will be communicated to the city of Tshwane health directorate to make them aware of the experiences regarding the provision of reproductive health services of both clients and HCPs who provide reproductive health services including the prevention of HIV and AIDS in primary healthcare settings. The study also aims to inform the health personnel in Tshwane about establishing interventions to make reproductive health services accessible to informal settlement residents through the involvement of residents and thereby educate residents about the prevention of HIV and AIDS.

\section{Research method and design}

The researcher used a qualitative, phenomenological design. The phenomenological enquiry enabled the researcher to engage in dialogue with participants to explore and describe their lived experiences regarding the provision of reproductive health services including the prevention of HIV/AIDS in a selected primary healthcare setting in Tshwane.

\subsection{Population}

The population comprised females who made use of the reproductive health services (clients) and the reproductive healthcare provider (HCP) in selected PHC settings in Tshwane, Gauteng. There was triangulation of the sample population as there were two groups of populations and this added to the trustworthiness of the findings (Polit \& Beck, 2012, p. 584).

\subsection{Sample and sampling}

Purposive sampling was used to select 23 females who used the reproductive health services and ten healthcare providers in selected PHC settings. In-depth individual interviews were conducted with seven clients and four healthcare providers. Due to a lack of depth in findings with clients, three focus group interviews were conducted. The number of participants in the three focus groups was: five, five and six participants (clients) respectively. One focus group interview was conducted with six healthcare providers to confirm data saturation as only four participants were included in the in-depth individual interviews.

\subsection{Inclusion criteria}

Setswana- or English-speaking clients who were between the ages of 18 and 49 years and who used the reproductive health services in a PHC setting were included. Healthcare providers (HCPs) who had one year experience and more and who provided a service in the reproductive health services in the PHC setting were included.

\subsection{Data collection and data analysis}

Data collection was divided into two parts. Part 1 of the data collection process comprised in-depth individual interviews with females who used reproductive health services and reproductive health care providers. Part 2 consisted of focus group interviews with females who used reproductive health services and reproductive health care providers. Data collected during the in-depth individual interviews with clients lacked depth, and thus focus group interviews were conducted. Data that emerged during the focus group interviews had depth and led to data saturation as it provided similar data as the in-depth individual interviews (Polit \& Beck, 2012, p. 538). The two data collection methods used added to the credibility of the findings.

The question that was asked during the individual indepth interviews and focus group interviews was the following:

"What are your experiences with regard to the provision of reproductive health services and the prevention of HIV and AIDS in primary healthcare settings in Tshwane?"

The individual and focus group interviews were audiotaped and field notes were taken. Audiotaped interviews were then transcribed verbatim. The Setswana interviews were translated into English by the researcher who is conversant in both languages.

\subsection{Data analysis}

Data analysis was carried out by the researcher according to Tesch's method, and themes and categories were identified (Tesch, 1990, pp. 95-97). Data from Part 1, the individual interviews, was analysed before the focus group interviews were conducted and later the data from the two sample populations was integrated as similar themes and categories emerged. Data from Part 2, the focus group interviews, was also analysed and integrated as both sample populations revealed similar themes and categories. Consensus that data saturation had occurred was reached by the researcher and supervisors. Finally, transcripts of the data from both the 
individual and focus group interviews were sent to the external coder for analysis. After agreeing on themes, categories and subcategories with the external coder, the data from both interview sources was integrated as themes and categories were found to be similar.

\section{Trustworthiness}

The researcher ensured credibility, dependability, transferability and confirmability by including strategies to ensure trustworthiness (Polit \& Beck, 2012, p. 584). Credibility was ensured through prolonged engagement; triangulation of data-collection methods included persistent observations, and individual and focus group interviews. Dependability was ensured through detailed descriptions of the research methodology and findings through a literature control. Supervisors and external coders were involved to ensure confirmability, while the rich description of the demography, research process and findings, including direct quotes, confirmed transferability.

\section{Ethical principles}

The researcher obtained written approval to conduct the study from the faculty's ethics committee of a university in Gauteng and from the research department of the City of Tshwane Metropolitan Municipality. Informed consent was obtained from the managers of the clinics where the study was conducted, as well as from the participants. The principles of beneficence, justice and dignity were observed throughout the study. The participants were not exposed to any harm as data collection included interviews only and no other treatment was administered. Participation was voluntary and all participants gave informed consent after the purpose and objectives of the study had been fully explained to them.

\section{Findings}

The following six themes emerged from the data: the impact of policies for health sector transformation on staff provision, the impact of staff shortage for reproductive health services on clients, the dual needs of clients accessing reproductive health services, mandatory overtime for healthcare providers, the need for community-based care to provide reproductive health services, and support needed for the provision of community-based care. The following abbreviations will be used to differentiate between the participants, individual interviews and the focus groups interviews: healthcare provider (HCP); female who made use of PHC services (client); individual interviews (InI) and focus group interviews (FGI).

\subsection{The impact of policies for health sector transformation on staff provision}

The informal settlements are densely populated and this means that increasing number of people are accessing the primary healthcare services. Access to PHC clinics should be free as stated in the Batho Pele principles (Jooste, 2010, p. 33), however, this is contributing to client overcrowding. The experiences of the participants from both sample populations during Parts 1 and 2 of the data collection were similar. Staff shortages affected clients as they were left unattended while HCPs experienced "hectic" work situations as the number of clients they had to attend to was very high. The healthcare providers (HCPs) reported that being short-staffed led to overwork. One HCP gave evidence of overwork and said:

HCP1 (InI): We are short-staffed; we see large numbers of patients at the clinic; we consult a total of 12000 patients during some months, it is hectic.

This was confirmed by a client during an individual interview who said:

Client7 (InI): Sometimes when one asks why we are not attended to, [it] is only then [that] you get a reason for waiting so long. They say they are few or so.

During the focus group interviews the clients commented on the effect of staff shortages on them:

Client (FGI2): The time we spend at the clinic is long ... (silence), very long sometimes one spends the whole day at the clinic. When I say the whole day I mean waking up at 05:00, leaving home at 05:30 and one arrives at the clinic at 06:00 to be among the first in the queue. But you find that the queue is already long as we follow the same queue, as such one spends a long time in the clinic. There was a day that I was seen at 15:00. Where are the children who come back from school that time, they are alone. It cannot continue like this.

Another participant from the same focus group (2) corroborated this:

Client (FGI2): It (the queuing system) confuses us with all patients crowding at the same point and we spend a whole day here, we cannot afford this. Presently we are absent from work, and antenatal care needs regular visits, our employers may not release us.

Clients and HCPs were all affected by the increasing numbers of clients as there was patient overcrowding, long waiting times and sometimes minimal communication to update clients about reasons for the long waiting time. It appeared that HCPs were not aware that clients needed to be informed about the long waiting times, especially those who were employed or had children they needed to care for. Some participants, including those who attended antenatal care, mentioned that they might miss the next appointments. Scheduled antenatal visits, according to Basic Antenatal Care (BANC), are needed to closely monitor maternal and foetal health, and women are required to come to the clinic at 20, 26, 32 and 38 weeks of gestation (Pattinson, 2007, pp. 15-23). One of the factors leading to long waiting times, such as staff shortages, is still an issue even though the National Department of Health's Strategic Plan 2010/11-2012/13 
(NDoH, 2010, p. 8) has endorsed human resources management, planning and development as strategy number five of its ten-point plan to reduce these waiting times.

During individual interviews with HCPs it was found that staff shortages were also affected by policy changes as health promoters were no longer employed. The HCPs reaction to these policy changes is summarised in the following quotes:

HCP1 (InI): The different management levels in the PHC provision are a problem because they [health promoters] are employed by the provincial government.

The same participant added:

It was worse because of the moratorium on the appointment of health promoters ... they managed to close the gap of lack of knowledge. We have one health promoter in the clinic, she is presently on leave.

\section{Another HCP stated:}

HCP4 (InI): The health promoter we have is on leave, there is no relief, no new appointments, the city council does not have health promotion on their organogram.

The DHS devolution caused different management to be involved in the appointment of health promoters. This apparently impacted negatively on the PHC setting in that no health education could be provided due to the moratorium on the appointment of healthcare promoters. Some policy changes such as the devolution and decentralisation of the District Health System (DHS) (Van Rensburg, 2009, p. 181) also affected reproductive health services. These policies have led to a shortage of health promoters who are a category of HCPs who provide health education in PHC settings. Appointments in this category have been put on hold.

\subsection{The impact of staff shortages on reproductive health services re clients}

There were negative reports related to the impact of staff shortages that affected health education provision. Sometimes clients wait for long hours without being provided with any health education. One participant said:

Client (FGI 2): Some clinics give health education on HIV and AIDS but not here.

Another participant confirmed the lack of health education by HCPs:

HCP1 (InI): Health promoters helped with health education and addressed common problems for reproductive health.

Another participant said:

HCP2 (InI): We offer health education for patients as family planning group, ANC patients, VCT patients, individualised care and health education is impossible to offer. Although individualised care is low, I usually ask the patients if there is anything they want to talk about, some do open up, they say their problems. Patients have problems I wish I had time to talk to more patients and that more patients may open up.

Participants expected to be provided with health education on HIV and AIDS, however, to their dismay this was not happening even though HIV and AIDS are major health problems. The absence of health promoters was thus the reason for the lack of health education provision. It seems as if the women were not given information on family planning, and antenatal care was sometimes also not provided for by health education. A shortage of trained health education staff and the lack of time to provide health education were reported as barriers in a study conducted in Saudi Arabia (Asiri, Bawazir, \& Jradi, 2013, p. 3).

\subsection{The dual needs of clients accessing PHC services}

In April 2010 President Zuma launched the HIV Counselling and Testing (HCT) initiative to target 15000000 people from 2010 to June 2011 (Community Media Trust [CMT], April 2010). Additionally, the policy on the prevention of mother-to-child transmission (PMTCT) promotes the idea that the HCP should routinely initiate voluntary counselling and testing (VCT/HCT) of all pregnant females (DoH, 2010, p. 1). In a progress report, deputy-president Dr Motsoaledi confirmed that 18000000 of the population had been tested months after the launch of HCT (Khumalo, 19 April 2013).

In terms of the above policies, it is therefore mandatory for healthcare providers to screen all clients utilising the reproductive health services for HIV. In this regard two HCPs made the following statements:

HCP2 (InI): The personnel are overloaded by patients for the following services: voluntary counselling and testing (VCT) and HIV counselling and testing ([HCT]), antenatal care (ANC). The patient's specific needs take time to cover and the HIV and AIDS counselling need time and patience.

HCP1 (InI): I am not able to tell the numbers of patients I consult, but most patients seen for common ailments are referred to VCT, among all adults we supposed to screen for HIV and AIDS risks, every sexually active patient is a client for reproductive health.

Healthcare providers are implementing the HCT and screening clients for HIV thus leading to longer consultation times and overburdened HCPs. And yet the integration of HIV/ AIDS management during reproductive health provision services is crucial because of the high morbidity rate of HIV/AIDS in the childbearing age group (Stevens, Webb, Davis, Corless, \& Portillo, 2008, p. 413).

\subsection{Mandatory overtime for healthcare providers}

The community's demand for care influenced the working hours of the HCPs which is eight hours. Failure to provide reproductive healthcare to all clients within eight hours led to extended working hours, which included adding one and half hour daily and working on Saturdays (Gauteng Province Government [GPG], 2012/13, p. 39). Having the clinic open on Saturdays was mandatory. It adhered to the Batho Pele 
principles and addressed the needs of employed clients. The participants said:

HCP1 (InI): Sometimes during the week we cannot see all clients by $16: 00$ and we (the professional nurses) work beyond this time and some Saturdays we are forced to work.

Client7 (InI): If the clinic can open during Saturday for us who are employed to lessen the congestion we experience in the clinic it will be better.

The DoH guards against litigation by clients and ensures sustained provision of healthcare to clients and access by extending the working hours of the HCPs, i.e. by extending service provision hours. According to GPG (2013/13, p. 39), it is mandatory for clinics to provide access to clients and overtime is paid for any time worked over and beyond the 40$\mathrm{h}$ working week. PHC settings have to provide healthcare on Saturdays where indicated. As overtime was paid, the interviewed HCPs did not mind working overtime.

\subsection{The need for community-based care to provide reproductive health services}

The provision of reproductive health services did not include other initiatives such as community-based care due to staff shortages. According to the HCPs, community involvement was needed to facilitate the provision of health education. The focus of health education, as communicated by the HCPs, was to address teenage health problems and HIV/AIDS prevention. The HCPs commented as follows:

HCP2 (InI): I think there is a need for community-based health education; we at the clinic attend mostly to the provision of family-planning methods, and assessing pregnancy-related problems and others. There is little time for health education, especially with [the] shortage and absence of health promoters. I wish attention must be given to patients' knowledge.

HCP4 (InI): Reproductive health promotion programme need to reach out to the community. We need to address the problem of teenage pregnancy and HIV and AIDS. The adolescents I counsel in the clinic for VCT did not use the condom because the males refused to use the condom. Most adolescents are pregnant. A community-based programme led by the health professionals may help address such problems.

HCP3 (InI): At certain times I believe community involvement may solve the problems we experience while caring for the adolescents. Maybe we have to work with the community.

Participants believed that community-based care was important and should not be ignored as evidenced by the following comments:

HCP3 (InI): There is no school-based care collaborated with the clinic, no awareness campaigns for reproductive health promotion especially for teenagers. School-based programmes reduce teenage pregnancy rate. I think there is evidence of impact of such intervention specifically on teenage pregnancy reduction. Teenagers need help to prevent falling pregnant.

Client5 (InI): Community projects lower the rate of teenage pregnancy; when we taught the school children less girls got pregnant; they could go to the clinic and get family planning, or agree with the boyfriends to use a condom. We taught them how to communicate, negotiate in relationship and make positive decisions.

The participants were very motivated to start communitybased projects. Positive experiences by participants were recounted and they believed positive health outcomes could be attained. Such projects could lead to dialogue between adults and teenagers in order to reduce teenage pregnancy as well as HIV/AIDS. Moreover, providing community-based health education and talking to adolescents have yielded positive results as evidenced in a study conducted in Malawi where the reproductive health outcomes of adolescents, such as unintended pregnancy, STIs, HIV/AIDS, improved (Hanlon \& Standley, 2012, p. 246).

\subsection{Support needed for the provision of community- based care}

The women in this study desired to have a support network which would allow them to be engaged in discussions on issues such as the prevention of unintended pregnancy, STIs, HIV and AIDS. They felt that this would assist them to coach teenagers on these issues. Furthermore, the participants (clients) indicated that they needed social support networks and professional support that would enable them to have open discussions at home.

Professional support was also needed within families and communities to develop problem-solving skills and this need was expressed by one of the clients as follows:

Client2 (InI): Females need to be given information on a lot of things, we live in the community where role models are negative, family lives are unstable and relationships are falling apart. There is a need to help people how to solve problems.

The participant elaborated on the need for professional nurses to help and said:

Client2 (InI): We need nurses to help us talk about these things; females must be able to support each other. We need to be a caring society.

Participants wanted professional and organised assistance in the community such as school-based care to curtail teenage pregnancies. Moreover, they requested professional support which would empower them to become self-sufficient and would help them to solve their family and community problems. There is thus a need for family support especially where healthcare provision is limited in order to empower family members to deal with current health issues such as HIV/AIDS and teenage pregnancy as these issues appear to affect family health negatively (Khetani, Orsmond, Cohn, Law, \& Coster, 2011, pp. 7-8).

Two participants outlined the activities of social support as follows:

Client1 (InI): We must talk among ourselves as people in the community; sisters are busy; they cannot tell us everything, every woman must talk to her partner and children. 
During one focus group interview one participant said:

Client (FGI1): Sister, we need parents at home who have knowledge, who can guide children, who encourage open talks with their children and they communicate friendly to encourage children to report and ask anything from their parents.

The fact that the HCPs were busy and had not enough time to talk to clients motivated them to start a support group where family members as well as community members can talk and help each other in solving common problems.

Even though the women needed support to talk about their problems, some also needed to be assured of privacy:

Client (FGI1): I wish we had discussions like this frequently at the clinic. Where females meet to discuss their experiences with people they do not know. At the community where one lives you cannot be open and talk about your experiences because your neighbours will start gossiping about you.

Participants were eager to have support groups in the community; however, they were concerned that their discussions would not remain confidential and that their personal problems would be disclosed to the community. They feared being gossiped about by neighbours and needed reassurance that they could trust each other. Health problems such as HIV and AIDS, rape and abuse are often not talked about as society tends to stigmatise the affected families or individuals. Trust and confidentiality within a support network are needed in order for members to be open with each other and to feel free to disclose their health problems (De Villiers \& Ndou, 2008, p. 6).

Linking the lack of caring and support in the community to other factors such as poverty, one HCP gave a detailed account of a situation to illustrate the interconnection:

HCP2 (InI): You know there is also a moral and poverty problem. There is a problem of child trafficking; the school girls reported that there is a female who lures school girls into a car of a male. After travelling a certain distance, the woman climbs off and the male drives away with the school girl. The school girl is raped and given R100.00. The school girl who reported the incidence tested HIV positive.

The HCP was disappointed by some parents in the community who, instead of providing support to poor and vulnerable girls, they exposed them to abusers. Minimal amounts of money are used to exploit poor and vulnerable girls. One hundred rands is obviously far too little to meet the needs of a teenager, especially an HIV-positive teenager. A study conducted in Nigeria found that the poorer the children, the higher they are at risk for human trafficking as money becomes a way to attract children. Moreover, when drugs are involved, money is used as an incentive to lure children into dangerous situations (Aransiola \& Zarowsky, 2014, p. 406).

\section{Discussion}

After the first democratic elections in 1994, the Abolition of Racially Based Land Measures Act of 1991(Act No. 108 of
1991, Chapters i-viii) repealed the Group Areas Act (1950) and gave South African citizens freedom of movement and this lead to the mushrooming of informal settlements (Van Rensburg, 2009, p. 198). This in turn led to an overburdening of the health services with serious staff shortages being experienced.

Furthermore, staff shortages are also related to the devolution of healthcare services in South Africa which was intended to transform healthcare provision through decentralisation and the devolution of authority to provincial and local government levels (Van Rensburg, 2009, p. 141). The aim of the decentralisation of the District Health System (DHS) was to ensure accessible and equitable PHC services (Regmi, Naidoo, Greer, \& Pilkington, 2009, p. 361). However, in the setting of the current study a negative outcome was found. The decentralisation of the DHS and devolution of power as guided by the White Paper for the Transformation of Health Systems in South Africa (DoH, 1997) led to the absence of health promoters because the devolution of power to control finance was delayed (Van Rensburg, 2009, p. 141). Conversely, the local governments did not establish the structures needed to facilitate community participation (Shaikh et al., 2011, p. 225). The $\mathrm{NDoH}$ was committed to supporting the provinces to implement the human resource policy plan as determined by local needs (NDoH, 2010, p. 8); however, based on the evidence of the participants in the current study, staff provision was not achieved. In 2010, according to the $\mathrm{NDoH}$ (2010, pp. 15 \& 22), there were 55309 professional nurses - not nearly enough to meet the country's dynamic and diverse health needs of about 53 million people, especially with the high prevalence of HIV and AIDS which accounts for $31 \%$ of the disease burden in South Africa.

According to the HCPs, staff provision was affected by the increasing number of clients who had to be provided with healthcare in PHC settings. The National Department of Health Strategic Plan 2010/11-2012/13 (NDoH, 2010, pp. 14-15) observes the WHO's norm for PHC provision as 10000 clients per clinic. This was clearly not the case at the study setting since client numbers were sometimes 12000 a month. When interviewed on 23 February 2014, Masemola-Yende, a clinic manager, stated that it is suggested that the staff/patient ratio in the PHC setting of the Gauteng Department of Health $(\mathrm{GDoH})$ is $1: 35$. This means that some PHC clinics would have different needs for staff based on the number of clients who access the PHC service. Therefore the anticipated increase in client numbers should be considered when providing staff in PHC settings. In Zambia when a free public health service policy was adopted, an increase in client numbers of more than 50\% was observed (Masiye, Chitah, Chanda, \& Simeo, 2008, p. 3). To provide healthcare to the increased number of clients, a substantial service expansion to provide human resources and the erection of new clinics for the population would be thus needed to ensure that PHC service provision is within the WHO norm (Van Rensburg, 2009, p. 182).

The increase in the HIV and AIDS morbidity rate also contributes to the observed high number of clients due to dual diagnoses having to be integrated in primary health settings. Considering that 3.3 million out of the 5.3 million people living with HIV/AIDS in South Africa are female, it cannot be disputed that HIV screening is essential (DoH, 2010, p. 2). In 
this study it was found that the provision of care to include dual health needs led to long consultation times and, consequently, mandatory paid overtime. Stevens et al. (2008, p. 413) point out that in the USA mandatory overtime to provide dual care to HIV clients led to stress and burnout in nurses and many were prompted to leave nursing for other professions. According to Uebel, Guise, Georgeu, Colvin, and Lewin (2013, p. 11), overtime was caused by the extended needs of HIVpositive clients as they had more potential illnesses, treatment side effects and emotional aspects to consider. These clients therefore required longer and more complicated consultations than clients with other chronic diseases. In Africa it was noted that staff shortages due to overwork and overtime in countries such as Ghana, Kenya, Zambia and Mozambique led to the shortage of qualified healthcare providers as they resigned due to heavy burden of work (Bharat \& Mahendra, 2007, p. 100). Fortunately, no HCP in the current study verbalised their intention to resign.

Furthermore, monthly or fortnightly visits to the antenatal clinics increases the number of clients at PHC settings and could consequently affect clients' employability or even result in job loss. Clients who were employed found the operating hours of the services inconvenient because consultation times coincided with their own working hours (Jacobs, Ir, Bigdeli, Annear, \& Van Damme, 2012, p. 291). In addition, a study conducted in a PHC centre in Panchmahal in the district of Gujarat in western India revealed that clients were dissatisfied due to the long waiting time and thus they simply did not make use of the PHC services (Chandwani, Jivarajani, \& Jivarajani, 2010, p. 7). Long waiting times were reported as a threat to employed clients as they could not afford to spend the whole day at the clinic. Clients in this study experienced the effects of staff shortages as they had to wait for long times as compared to the norm of $2 \mathrm{~h} 40$ min hours waiting time in Gauteng provincial health institutions. Only $75 \%-80 \%$ of the PHC settings had a waiting time of 2-3 h (GPG 2012/13, p. 30).

The participants expressed that community-based care should be provided in order to address staff shortages and community-based reproductive health problems. This sentiment is supported by Satterthwaite (2011, p. 2) who confirms that the informal settlement residents need to work together with government to establish community organisations. Added benefits of community participation include clients saving on transport, working together with a culturally acceptable group, access to health education is assured and community members are empowered. Through community participation access to household reproductive health challenges can also be addressed (Jacobs et al., 2012, p. 292). In South Africa, the Khanya community-based programme is successful in improving health outcomes related to HIV/AIDS due to the continuous training of community-based workers (Nxumalo, Goudge, \& Thomas, 2013, p. 225). Barriers to community-based work were related to lack of trust. As HIV/ AIDS clients are stigmatised, participants in this study did not have the trust to share their reproductive health problems with neighbours. Disclosing one's status commonly leads to stigma and discrimination in the community and may lead to being ostracised (De Villiers \& Ndou, 2008, p. 6).

The participants in the current study believed that the creation of positive dialogue in community structures and the identification of barriers would help to overcome some of the issues uncovered in this study. Involving community members in making decisions regarding matters central to their health is a decidedly positive step towards transcending cultural and health provision barriers (Hardina \& Obel-Jorgensen, 2009, p. 98). In Nepal, for example, poor women and excluded groups were empowered when they started to participate in district planning as their representation on the decisionmaking, management and service planning committees was mandatory by law (Regmi et al., 2009, p. 414). The current study findings indicate that cultural barriers, for example the lack of open discussion between partners, parents and children, need to be addressed in order to ensure decision making and representation by all in community programmes. The availability of individual support would provide families with the skills and confidence to manage their health challenges, while social support could be used as a tool to promote community-based care. Families also need professionals to advocate for their needs regarding the provision of adequate care (Khetani et al., 2011, pp. 7-8).

It is clear that there is a need for accessible services which puts pressure on the South African government to consider the delivery of reproductive health services by knowledgeable and trustworthy community members.

\section{Conclusion}

The preceding discussion has highlighted the experiences of women using the reproductive health services, and the experiences of HCPs who provide the services in the PHC setting. The women who all lived in informal settlements were aware of the inability of the PHC setting to provide adequate reproductive healthcare that met their needs. Moreover, the HCPs acknowledged that the provision of healthcare was negatively affected by policies. The ability of community members to learn how to coach teenagers and support each other was identified as an asset to be used to bridge staff shortages and increase health outcomes. It became evident that clients were eager to be involved in providing care for their own good. Clients were aware of the effect of staff shortages on their reproductive health and could identify focus areas for community involvement. The reproductive health problems mentioned by participants should be the focus of communitybased care so that initiatives to provide reproductive health services are based on inputs from the providers and consumers of these services.

The following conclusions are based on the preceding discussion. The integration of inputs from the people at grass roots level during policy development is an important step to ensure that informal settlement residents are provided with accessible reproductive health services. Residents of informal settlements have not yet developed social support networks. The provided reproductive health services are currently not able to address teenagers' reproductive health problems and thus professional support is urgently required. A community that is involved in planning healthcare provision and is supported in developing skills to care for its members will be empowered. It was found in this study that both HCPs and clients have convergent experiences with regard to the 
provision of reproductive health services and wanted to participate in community-based initiatives. Participation of community members in the provision of reproductive health could contribute to reducing the incidence of unintended pregnancy, STIs, and HIV/AIDS. Staff shortages in PHC settings may be bridged if the community receives support to participate in their reproductive health promotion.

It is recommended that future studies that include more than one informal settlement be conducted on the provision of reproductive health services and challenges to prevent STIs, HIV and AIDS. The insight of community members with regard to their reproductive health needs to be explored further to design a community-based care programme that will meet their needs. Reproductive healthcare provision including the prevention of HIV/AIDS should be a priority for informal settlement's residents, and sustained contact with community members to mitigate the factors that make them vulnerable needs to be promoted.

One limitation of the study was that it was conducted in only one informal settlement area with a small number of participants.

\section{R E F E R E N C E S}

Abolition of Racially Based Land Measures Act 108 of 1991. Retrieved from http://www.plato.org.za/pdf/legislation/ Abolition\%20of\%20Racially\%20based\%20Land\%20Measures\% 20Act\%20108\%20of\%201991.pdf.

Aransiola, J. O., \& Zarowsky, C. (2014). Street children, human trafficking and human security in Nigeria: competing discourses of vulnerability and danger. African Population Studies, 27(2), 398-411.

Asiri, N., Bawazir, A. A. A., \& Jradi, H. (2013). Patients' satisfaction with health education services at primary health care centers in Riyadh, KSA. Journal of Community Medicine \& Health Education, 4(1), 1-5.

Bharat, S., \& Mahendra, V. S. (2007). Meeting the sexual and reproductive health needs of people living with HIV: challenges for health care providers. Reproductive Health Matters, 15(suppl 29), 93-112.

Bongaarts, J., \& Sinding, S. (2011). Population policy in transition in the developing world. Science, 574-576, 29 June.

Chandwani, H. R., Jivarajani, P. M., \& Jivarajani, H. P. (2010). Consumer satisfaction about hospital services of a private medical hospital of Gujarat, India. The Internet Journal of Health, 8(1), 11-28.

Community Media Trust, (CMT). (2010). HCT campaign April 2010. Retrieved from www.cmt.org.za/siyanqoba/series-vi/hctcampaign.

De Villiers, L. D., \& Ndou, N. D. (2008). South African professional nurses' experiences of caring for HIV/AIDS patients. Africa Journal of Nursing and Midwifery, 10(1), 5-21.

De Wet, K., Wouters, E., \& Engelbrecht, M. (2011). Exploring taskshifting practices in antiretroviral treatment facilities in the Free State Province, South Africa. Journal of Public Health Policy, 32(S1), S94-S101.

Department of Health (DoH). (1997). White paper for the transformation of health systems in South Africa. Pretoria: Government Printer.

Department of Health (DoH). (2012). Human resources for health strategy for the health sector South Africa (2012/2013-2016/2017). Pretoria: Government Printer.
Department of Health, (DoH). (2010). Clinical guidelines: Prevention of Mother to Child Transmission (PMTCT) (2nd impression). Pretoria: Government Printer.

Department of Housing and Settlement [DoHS]. (2009). The national housing code, incremental interventions, the upgrading of informal settlements (Vol. 4). Pretoria: Government Printer.

Department of Public Service Administration (DoPSA). (1997). Notice No.14590. The white paper on transforming public service delivery (Batho Pele white paper). In Government Gazette (Vol. 388). Pretoria: Government Printer, 1 October 1997, No.18340.

Gauteng Provincial Government (GPG). (August 2009). Annual Report 2012/13. In terms of the public finance management act Rule 9.4(1) of the Gauteng legislature, standing Rules. Johannesburg: Government Printer.

Hanlon, B., \& Standley, E. (2012). Sexuality education for young people, health and welfare (pp. 245-248). Commonwealth Ministers Reference Book. Commonwealth.

Hardina, D., \& Obel-Jorgensen, R. (2009). Increasing social action competency: a framework for Supervision. Journal of Policy Practice, 8(2), 89-109.

Jacobs, B., Ir, P., Bigdeli, M., Annear, P. L., \& Van Damme, W. (2012). Addressing access barriers to health services: an analytical framework for selecting appropriate interventions in low-income Asian countries. Health Policy and Planning, 27(4), 288-300.

Jooste, K. J. (2010). The principles and practice of nursing and health care. Ethos and professional practice, management staff development and research. Pretoria: Van Schaik Publishers.

Kabiru, C. W., Beguy, D., Chrichton, J., \& Zulu, M. E. (2011). HIV/ AIDS among youth in urban informal (slum) settlements in Kenya: what are the correlates of and motivations for HIV testing? British Medical Council Public Health, 11(685), 1-12.

Khetani, M. A., Orsmond, G., Cohn, E., Law, M., \& Coster, W. (2011). Correlates of community participation among families Transitioning from Part C early intervention services QTJR. Occupation Participation and Health, 20(1), 1-10.

Khumalo, G. (2013). HCT Campaign to be revived 19.04.2013. Retrieved from http://www.sanews.gov.za/south-africa/hctcampaign-be-revived. South African Government News Agency.

Masemola, P.. (Clinic manager) (2014). Patient professional nurse ratio in primary health care settings in Tshwane, verbal report, 25, February 2014.

Masiye, F., Chitah, B. M., Chanda, P., \& Simeo, F. (2008). Removal of user fees at Primary Health Care facilities in Zambia: a study of the effects on utilisation and quality of care, with Health Economics Unit, University of Cape Town. In The Regional Network for Equity in Health in East and Southern Africa Equinet Discussion Paper 57, March 2008.

Merkel, S., Otai, J., Archer, L., \& Lynam, P. (2008). Improving quality, increasing access to reproductive health care in African urban slums: Community members linked to health care providers in the urban slums of Kenya. Nairobi: Jhpiego, an Affiliate of John Hopkins University, USA.

National Department of Health (NDoH). (2010). Strategic plan 2010/ 11-2012/3. Pretoria, SA: Government Printer.

Nxumalo, N., Goudge, J., \& Thomas, L. (2013). Outreach services to improve access to health care in South Africa: lessons from three community health worker programme. January 2013 Global Health Action Journal, 219-226. AUTHOR, PLS CHECK DATES.

Pattinson, R. C. (2007). Basic antenatal care handbook. MRC maternal and infant health care strategies. Pretoria, SA: Research Unit Obstetrics and Gynaecology Department, University of Pretoria.

Polit, F., \& Beck, C. T. (2012). Nursing research: Generating \& assessing evidence for nursing practice (9th ed.). Philadelphia: Lippincott Williams \& Wilkins. 
Regmi, K., Naidoo, J., Greer, A., \& Pilkington, P. (2009). Understanding the effect of decentralisation on health services: the Nepalese experience. Journal of Health Organization and Management, 24(4), 361-382.

Satterthwaite, D. (2011). Upgrading dense informal settlements; the potential for health and well-being. Cities, Health and WellBeing, 1-3. November 2011.

Scott, R., \& Harrison, D. (2009). A gauge of HIV prevention in South Africa, 2009, in brief Love Life. Sandton, SA: Department for International Development.

Shaikh, S., Naeem, I., Nafees, A., Zahidie, A., Fatmi, Z., \& Kazi, A. (2011). Experience of devolution in district health system of Pakistan: perspectives regarding needed reforms. Journal of Pakistan Medical Association, 62(1), 28-32.

South African Broadcasting Company [SABC] News. (2013). Channel 192, Bekkersdal local service delivery unrest, September, 2013.

Statistics South Africa. (2013). Statistical release P0302, Mid-year population estimates 2013. Pretoria: Government Printer.
Stevens, L. C., Webb, A. A., Davis, S., Corless, I., \& Portillo, C. (2008). HIV care shortages highlighted in national meeting. Journal of the Association of Nurses in Aids Care, 19(6), 412-414.

Taleshi, M. (2009). Informal settlements and sustainable urban development. Case study: Metropolis of Mashhad in NorthEastern of Iran. World Applied Sciences Journal, 7(10), 1235-1238.

Tesch, R. (1990). Qualitative research: Analysis types and software tools. New York: The Falmer Press.

Uebel, K., Guise, A., Georgeu, D., Colvin, C., \& Lewin, S. (2013). Integrating HIV care into nurse-led primary health care services in South Africa: a synthesis of three linked qualitative studies. British Medical Council Health Services Research, 13(171), 1-11.

Van Rensburg, H. C. J. (2009). Health and health care in South Africa. Pretoria: Van Schaik Publishers.

Vearey, J. (2011). Challenging urban health: towards an improved local government response to migration, informal settlements, and HIV in Johannesburg, South Africa. Global Health Action, 1-10. June 2011. 